\title{
Zonas transfronteiriças, delimitação socioespacial e territorial do Estado: o caso da cidade de Jimaní (República Dominicana) e posto fronteiriço de Malpasse/Fonds-Parisien (Haiti)
}

\author{
Transborder areas, socio-spatial and territorial delimitation of the State: the case of the city \\ of Jimaní (Dominican Republic) and border post of Malpasse / Fonds-Parisien (Haiti)
}

\author{
Guerby Sainté \\ Mestrando em Geografia \\ Universidade Estadual de Campinas (UNICAMP), Campinas/SP, Brasil \\ guerby20102010@gmail.com
}

\begin{abstract}
Resumo
Este trabalho tem como principal objetivo realizar uma discussão sobre a fronteira entre o Haiti e a República Dominicana partindo de uma reflexão sobre as zonas de fronteiras e a dinâmica socioespacial e territorial no caso da cidade de Jimaní e o posto fronteiriço de Malpasse/FondsParisien. Essas relações mantidas na fronteira dos dois países são relevantes para a dinamização socioespacial e a formação territorial nas escalas nacionais dos Estados. Percebermos que a dinâmica da economia local criada na fronteira permite que as populações comercializem bens e serviços, tornando-se atrativas ao se observar o movimento da mercadoria binacional. Buscamos, então, analisar, por processo de abertura e fechamento da fronteira, os principais papéis da fronteira na política da economia urbana voltada a uma desaceleração ou aceleração da economia das cidades fronteiriças. Sendo assim, a economia promovida na fronteira visa à mudança de escala, e, portanto, busca-se analisar as realidades socioculturais regionais em condições de criar identidades e estruturas econômicas de maior valor agregado nas relações comerciais entre esses Estados.
\end{abstract}

Palavras-chave: Fronteira, Estado, território nacional, população de fronteira.

\begin{abstract}
This work has as main objective to carry out a discussion about the border between Haiti and the Dominican Republic. Starting from a reflection on the zones of sources and the socio-spatial and territorial dynamics in the case of the city of Jimaní and the border post of Malpasse/FondsParisien. These relations maintained at the border of the two countries are relevant for socio-spatial dynamization and territorial formation in the national scales of the States. We realise that the dynamics of the local economy created at the border allows the populations to market goods and services, becoming attractive when observing the movement of the binational merchandise. We seek to analyse, by process of opening and closing the frontier, the primary roles of the frontier in the urban economic policy aimed at a slowdown or acceleration in the economy of the border cities.Thus, the economy promoted at the frontier aims at a change of scale, and then, we will seek to analyse regional socio-cultural realities capable of creating identities and economic structures of more significant value added in commercial relations between states.
\end{abstract}

Keywords: Border, State, national territory, border of population. 


\section{INTRODUÇÃO}

O objetivo desse trabalho é discutir sobre as zonas transfronteiriças como uma delimitação socioespacial e territorial do Estado, tendo como foco a cidade de Jimaní e o posto fronteiriço de Malpasse/Fonds-Parisien. Alguns autores, como Jacques Ancel (1938), Foucher (1991), Raffestin (1974), Mezzadra (2016), Alfonso (2005) trazem uma abordagem de que a fronteira é considerada uma linha que delimita dois Estados soberanos, marcando como um espaço de sobrevivência e de limite da jurisdição do poder estatal no território. Esse espaço ou território representa um elemento fundamental (coração) da questão geopolítica e geoestratégica. Portanto, trata-se de um espaço que é proibido, perdido, cobiçado, negociado, sonhado e controlado, mantendo relações de trocas e de dominação entre as nações.

Às vezes a fronteira apresenta algumas restrições econômicas pelo fato de que elas apresentam fluxos migratórios de mão de obra e dos circuitos de atividades comerciais. A reflexão sobre o território para manter as formas de organizações do espaço econômico faz com que a mobilidade das pessoas se entrelacem com os limites e, porventura, produza novas configurações espaciais. Por essa razão, há a necessidade de controle, administração e gestão das fronteiras, levando os Estados a implementarem uma visão do espaço geométrico e ordenado.

\section{ESTADO, TERRITÓRIO, ESTADO, TERRITÓRIO, ZONAS DE FRONTEIRAS DA CIDADE DE JIMANÍ E O POSTO FRONTEIRIÇO DE MALPASSE/FONDS-PARISIEN}

A fronteira pode ser considerada como uma linha que limita o espaço sobre o qual se estende a soberania nacional (GOTTMANN, 1975). Nesse contexto, Raffestin (1993) ressalta que a noção de fronteira no Estado moderno atingiu um controle territorial absoluto. Para que isso se realizasse de tal forma, ela tem de cumprir uma série de exigências específicas, dentre as quais a mais relevante é a delimitação ou linearização da fronteira. A prática de linearização é uma das ferramentas e políticas importantes para a delimitação das fronteiras territoriais de dois Estados. Porém, para que esses Estados possam existir, precisam de uma população que se estabeleça num território para exercer sua própria soberania. Para Foucher (1991), as concepções de fronteiras podem ser representadas como as continuidades territoriais, com função de demarcação política. Elas são instituições estabelecidas por decisões políticas, concertadas ou impostas, e regidas por textos legais que permitem que o Estado exerça sua função de controle, de poder e de sua soberania sobre esse território.

Nesse contexto, a fronteira exerce um papel na história política entre os Estados nacionais e do limite de soberania de poderes, ela se encarrega do vivido e das interações entre as populações em zonas de fronteiras. Além disso, a noção de fronteira é vinculada à percepção do território como 
uma instância político-administrativa formal, sob o domínio do Estado (FERRARI, 2014). Essa concepção de dominação vem concebendo a fronteira e o território numa outra dimensão, que envolvem visões mais amplas, incluindo aquelas não hegemônicas, e se opõem ao próprio Estado (SILVA; TOURINHO, 2016).

De certo modo, o Estado passa a exercer um controle sobre porções do espaço, constituindo territórios, seja no sentido mais político do termo, seja na perspectiva simbólica. É da necessidade de controle sobre o território que emergem as noções de fronteiras, manifestando-se como a expressão espacial do uso político do território (CATAIA, 2008). Cabe ressaltar que a fronteira poderia ter múltiplos e variados efeitos e, portanto, era representada mais como um fato social do que um fato espacial stricto sensu. Entretanto, a execução e a gestão do projeto social pressupõem a posse da soberania nacional e territorial determinada por um modelo de fronteiras, estabelecendo limites ao campo relacional. Dessa forma, essas relações estão transcritas no tempo e no espaço. Porém, a fronteira não delimita exclusivamente o território stricto sensu, mas também espaço-temporalmente, determinando, por um arranjo de tempo e de espaços operatórios, lugar da realização de um sistema de relações, de disputas e de poder (RAFFESTIN, 1974).

No mesmo seguimento, as fronteiras passam a condicionar o ambiente de vida que depende em grande parte do status que lhes é concedido pelas autoridades políticas, além do modo como são praticadas pelos habitantes de ambos os lados da fronteira. Essa concepção de fronteira é considerada como um instrumento que depende de condições sociopolíticas e condições socioeconômicas (MOUDDEN, 2006). Portanto, a fronteira é uma reflexão ou projeção das preocupações do Estado nacional.

Porém, essas consequências específicas criam fenômenos que estão além do controle do governo central. Nesse âmbito, a fronteira tem capacidade para criar ou destruir ambientes vivos sem uma intenção consciente que preceda essas criações ou destruições. Assim, essas margens territoriais têm uma vida própria que resultam de um confronto de diferentes sistemas; também, nelas pode existir uma diferenciação absoluta porque a impermeabilidade é completa. Isto é, uma homogeneização por osmose (MOUDDEN, 2006; GUICHONNET; RAFFESTIN, 1974).

Ademais, a fronteira não resulta apenas do equilíbrio, ela também é modelada nas forças vitais de dois povos. Ela é plástica porque tem um valor relativo simples, de acordo com a função efêmera que lhe é atribuída pelo grupo que enquadra e por um tempo que a mantém. Assim, ela pode parecer apenas um limite suave e temporário, às vezes rígida e permanente, para as atividades de uma sociedade. Ela se fecha, de modo plástico, não nos obstáculos aos quais se agarra para se fixar, mas no que é agitada por dentro de um território (ANCEL, 1938) e de um espaço geográfico.

Na percepção de Moraes (2005), o território representa um espaço social que não pode existir sem uma sociedade que o crie e que o qualifique. Logo, inexiste como realidade puramente 
natural, sendo construído com base na apropriação e transformação dos meios criados pela natureza. Para Ratzel (1982), o território é determinado pelo domínio de um grupo humano, definindo pelo controle político de um dado âmbito socioespacial e territorial. Em relação a isso, Moraes (2005) ressalva que os territórios se mantêm apenas pelo recurso à força e à violência, envolvendo também instâncias de legitimação de domínio e de poder de Estado praticado, o que redunda em formas jurídicas de reconhecimento dos direitos de soberania interna e externamente ao espaço. Assim, esse território é determinado por uma construção política que, portanto, deve ser retratada por meio de pactos e disputas sociais e por meio de uso.

Por meio do uso do território, as formas hierárquicas e de ocupação entre os lugares explicam os efeitos de lutas, violências, hegemonia e atos políticos. Além disso, a produção do espaço pode ser observada como um processo teológico, fortificada em projetos e orientada por opiniões. Porém, a construção do território pode envolver um conjunto de sistema de ações, um possível caminho para análise da formação social e histórica de um país. Em relação a isso, o território nacional resulta e passa por um longo processo histórico principiado pelo processo de Paz de Westfália (1648), ao permitir que o Estado tome para si o território como o monopólio legítimo do exercício do poder político (MORAES, 2005). Essa concepção hegemônica de território continua a ser essencial no momento em que a valorização diferencial de nações e regiões é agravada pelos impulsos globais (RIBEIRO, 2013).

Nessa perspectiva, a celebração histórica das condições propicia a vivência de homogeneidades nas vinculações sociais de produção por meio de uma hierarquização políticoespacial da sociedade. Assim, a região correlata à regionalização estimula interpretações que tocam as condições historicamente construídas da reprodução social e territorial (RIBEIRO, 2004). Numa eventual análise do território, o espaço passa a ser determinado como um fato social, produto da atividade humana que intromete no processo social, tanto pelo que aconteceu na história quanto pelo fato imanente de historicidade provável de ser imaginada. Portanto, cada pacto de configurações espaciais e técnicas relacionadas institui a particularidade produtiva de um espaço, sua virtualidade, sua limitação (SANTOS, 1982) e a valorização do espaço.

Segundo análise de Moraes (2005), tal valorização do espaço pode ser apreendida como processo historicamente reconhecido pela organização de território. Essa valorização pode ocorrer na relação de uma sociedade particular com seu espaço, num intercâmbio contínuo que pacifica essa localidade, materializando concomitantemente as formas de sociabilidade dominantes numa estrutura territorial e organizacional. Desse modo, Santos (2006) defende que o espaço seja definido como um conjunto indissociável de sistemas de objetos e de sistemas de ações. Através dessa ambição sistemática, imaginamos poder construir um quadro analítico unitário que permita ultrapassar tautologias e ambiguidades. 
Para Souza e Gemelli (2011), Território e Região são inseparáveis nas esferas da análise geográfica e, portanto, não podem ser estudados independentemente. Eles estabelecem uma relação apropriada na medida em que o deslocamento do território, envolvendo a territorialização, a desterritorialização e a reterritorialização, está estreitamente relacionado ao movimento de construção, desconstrução e de reconstrução de territórios mais recentes, contribuindo na reestruturação espacial.

A concepção do território é constituída em um conceito subordinado a outro mais abrangente, o espaço, determinado como uma forma de organização espacial. Portanto, a lógica da territorialidade passa a ser referida ao conjunto de práticas e suas expressões simbólicas e materiais capazes de garantir a apropriação e a permanência de um dado território por um determinado agente social, o Estado, os diversos grupos sociais e empresas (CORRÊA, 1997). Cabe ressaltar que tais práticas sociais dependem das circunstâncias e das condições imateriais e materiais que encaram e encontram limites associados à dinâmica da totalidade, contínua e instável configuração. Portanto, são geralmente representados os confins e vinculados à técnica que constroem fronteiras e que informam sobre a natureza dos projetos que conduziram a influência hegemônica, em seu confronto com outras ações dos agentes que disputaram seus conteúdos ou aquelas tantas vezes exclusivas na escala do cotidiano através de uma formação espacial (RIBEIRO, 2004; SANTOS, 2006).

Esse processo de destruições e construções realizadas faz parte daquele espaço, qualificase para as apropriações no tempo que está por vir. De fato, tal construção de um território é um processo de acumulação; a cada momento uma possibilidade e resultado, contínuo movimento. Portanto, a valorização do espaço aparece como horizonte teórico universal de investigação. Embora a formação territorial represente-se como um objeto empírico, o ajuste de essência naquela ótica angular atrai o movimento histórico. É uma ferramenta que busca compreender a valorização do espaço em manifestações singulares e, simultaneamente, faz a análise dos lugares (MORAES, 2005).

No âmbito de estudo da zona de fronteira, a questão que se considera aqui é a fronteira de Jimaní e o posto fronteiriço de Malpasse/ Fonds-Parisien, entre dois Estados soberanos. Na fronteira sul, está o Posto Fronteiriço de Malpasse e a cidade de Jimaní. O Município de Jimaní possui uma área de 2.006,39 km² e, em 2016, contava com uma população total de 16.510 habitantes (MATOS, 2016). A cidade mais próxima do Posto Fronteiriço de Malpasse é Fonds-Parisien, que, em grande medida, mobiliza o Posto nos momentos de troca de mercadorias. Essa cidade tem uma área de 493,7 km² e conta com uma população de 28.207 habitantes (IHSI, 2015). No Sul, o posto fronteiriço de Malpasse e a cidade de Jimaní são atravessados pela Rota Nacional $n^{0}$ 8, que faz a conexão entre as capitais Porto Príncipe e Santo Domingo. Esse fato coloca essa área de fronteira 
frente a um intenso fluxo de mercadorias em razão das maiores concentrações populacionais dos países (Figura 1).

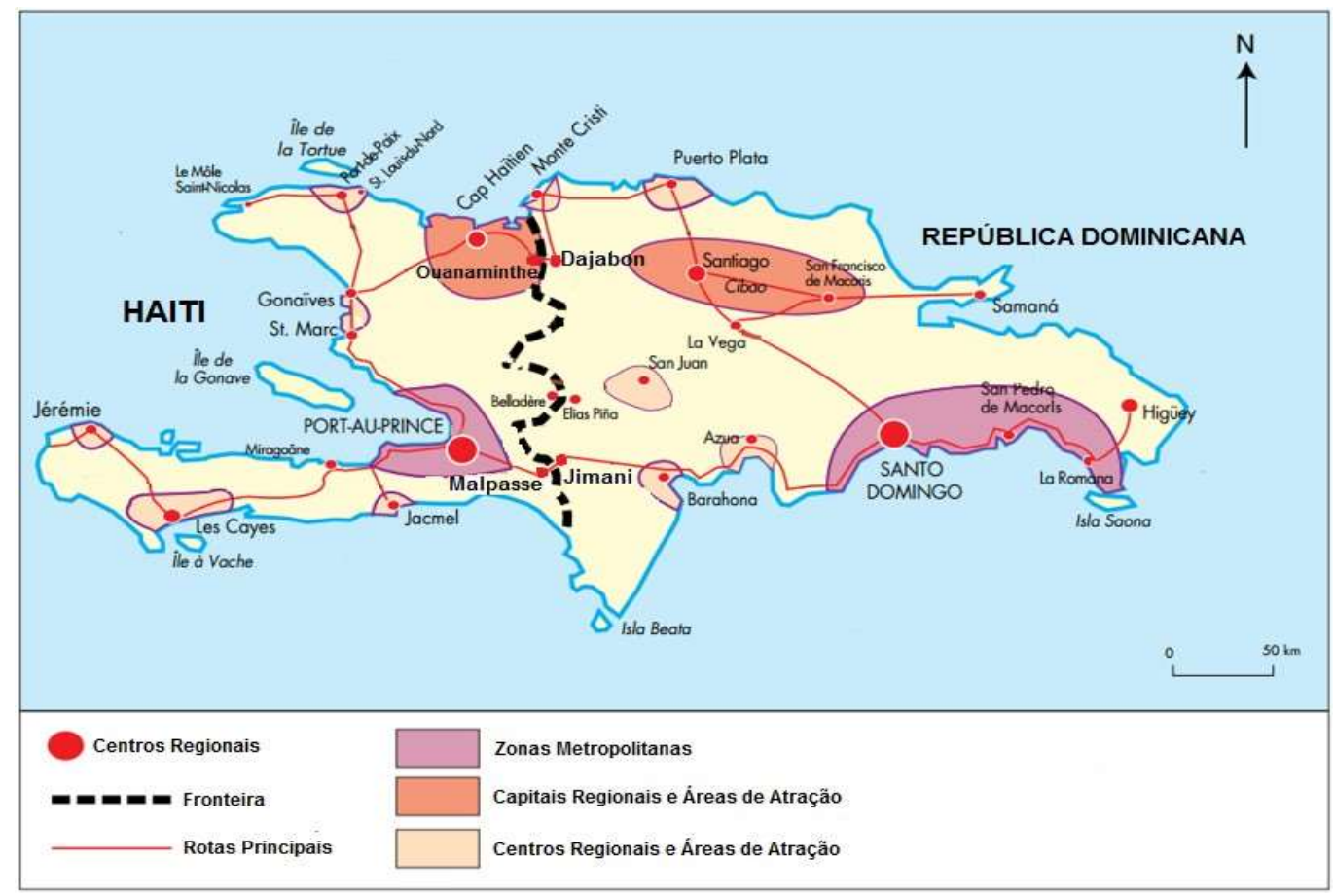

Figura 1 - Localização geográfica de Jimaní e Posto fronteiriço de Malpasse. Fonte: Une Île, deux États (THEODAT, 1998; SAINTE, 2018).

Em decorrência dessa análise, Cataia (2008) salienta que a delimitação políticoadministrativa estadual ou municipal, instituída nas fronteiras territoriais de um Estado ou de um país, estabelece um conjunto de planejamento e planos políticos e ações diversificadas. Ainda, podermos observar que esses planos políticos hegemônicos, que, na realidade, não são hegemônicos integralmente de um território nacional ou de um país, apresentam incompatibilidade. Tais mecanismos permitem, de fato, criar as fronteiras internas. Dessa forma, essas desintegrações se outorgam e, portanto, existem fronteiras internas geralmente concebidas através de projetos diferentes.

Esses movimentos separatistas se constituem por meio de uma construção social, todavia não podem possuir fraturas, dados os localismos e os regionalismos no qual compartem as rupturas territoriais. É nesse contexto que as fronteiras não são naturais, mas históricas. Na análise de Redon (2010), a fronteira passa a ter a distinção de ser legível na paisagem da ilha. Esta visibilidade devese, por um lado, às diferenças na exploração da área (plantação no Oeste e agricultura extensiva no Leste, de modo que a cobertura vegetal é menos densa no lado haitiano), e, por outro lado, à vontade política das autoridades dominicanas, ansiosas por demarcar claramente o território nacional. 
No lado dominicano, nota-se a onipresença militar nas fronteiras, que provoca impressão de sacralidade do território. Observa-se que as rotas que conduzem ao Haiti são marcadas com postos militares marcados por lombadas e barreiras removíveis. A figura 2 mostra a militarização da fronteira da República em Jimaní.

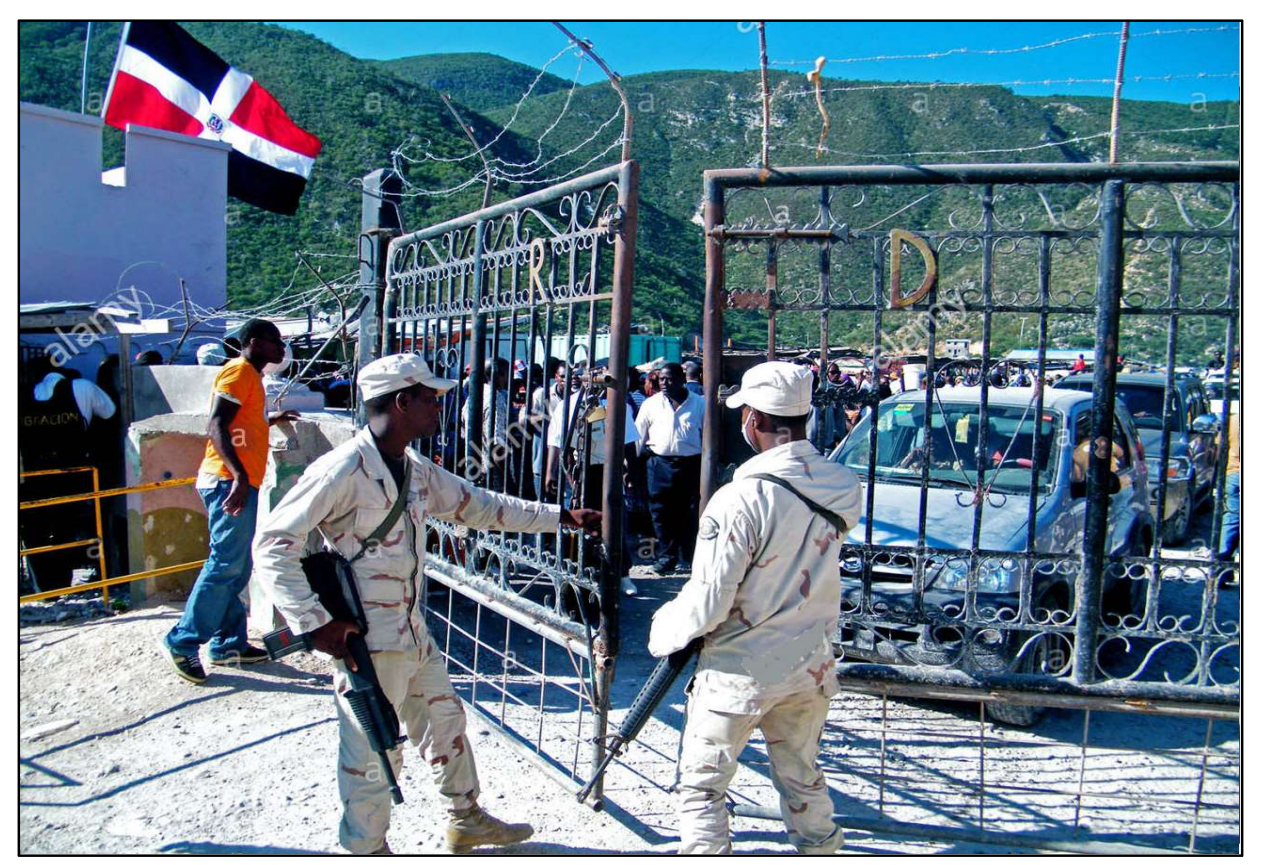

Figura 2 - Entrada da fronteira Jimani-Malpasse/Fonds-Parisien.

Fonte: Alamy Stock foto (2010).

Em meio a diversas divergências sociopolíticas e econômicas existentes entre os dois países, a fronteira passa a exercer um papel de zona camuflada na medida em que cada delimitação linear fixada corresponde a uma área geográfica. Contudo, essas áreas estão geralmente municiadas por uma série de armamentos que se transmutam em postos avançados com forças de vigilância fronteiriça; de controle, de proporção impenetrável para proteger o território nacional contra invasão.

Todavia, essas fronteiras relacionam-se atualmente à delimitação socioterritorial e espacial do Estado moderno, que se estabelecem como instrumentos de poder político dos Estados nacionais (FERRARI, 2014; RAFFESTIN, 1993), interferindo na busca de controle de fluxo de mercadoria e de comércio na faixa de fronteira. Sendo assim, essa busca de controle do território faz com que a fronteira não se constitua exclusivamente de uma linha de delimitação e de demarcação entre os Estados soberanos. Na realidade, é um lugar de interatividade entre duas populações movidas pelo processo de abertura e fechamento das fronteiras, de movimento de fluxo de pessoas, de migração, de mercadorias e de comércio que circulam e se estabelecem na zona de fronteira (REDON, 2010), que, às vezes provoca algumas disputas e problematizações devido à sua abertura e ao seu 
fechamento, como ocorre na região de fronteiras entre o Haiti e a República Dominicana, a ser discutido em seguida.

\section{ABERTURA E FECHAMENTO DA FRONTEIRA: PROBLEMATIZAÇÃO DA RELAÇÃO SOCIOESPACIAL E FLUXOS DEMOGRÁFICOS}

A fronteira entre Jimaní e Malpasse/Fonds-Parisien é um dos pontos de fronteira mais dinamizados e movimentados em relação a fluxo de pessoas e de cargas e mercadorias. Além disso, essas fronteiras representam um lugar estratégico para os dois países, que são historicamente desiguais. Assim, a via de transporte é praticamente um meio natural no exercício de intercâmbio entre o Haiti e a República Dominicana.

Contudo, nenhum dos países havia estabelecido um regulamento de trânsito terrestre transfronteiriço comum, como ocorre entre a maioria dos países adjacentes e entre os Estados circunvizinhos (HIDALGO, 2013). De acordo com Alfonso (2005), a abertura da fronteira tem um significado específico para o comportamento da fronteira como uma fronteira internacional, que deve ser levada em conta devido às suas implicações para o futuro. Portanto, ela aparece exclusivamente como um espaço coerente observado do exterior, enquanto no seu interior, em suas comunidades e atores, a periferia é percebida como uma cadeia de diferentes espaços socioculturais sem conexão entre eles.

Ademais, a região de fronteira internacional pode ser apresentada como uma posição geográfica singular, dada sua proximidade à linha-limite que separa os Estados. Portanto, ela é determinada como um lugar de interatividade, de encontro, de conflitos, de comunicação, e também onde ocorre um conjunto de sistemas territoriais assimétricos, de nacionalidades e de culturas diferentes dentre de um determinado espaço territorial e de interações socioespaciais (MACHADO, 2005).

Por meio dessas interações socioespaciais, de relações econômicas e políticas estabelecidas entre os Estados, a fronteira passa a existir e ter vida, funciona como um espaço permeável, membranoso, poroso, possibilitando o trânsito de diferentes componentes, apresentando uma feição categoricamente seletiva. É da "natureza" da fronteira que nela ocorram a passagem ou a interdição, o fluxo de movimento de pessoas, de troca de informação, de ideias, e pode ser interferida numa esfera de comunicação, com eventuais ruídos, estados de consciência, de substâncias, de objetos. Juntamente a essa particularidade, ela possui também uma representação na organização espacial de mais complexidade do território, na dispersão e na construção de significados do universo através de estrutura territorial do Estado (SILVEIRA, 2005).

Como a fronteira é gradualmente diferente, mesmo considerando as diferenças nos níveis de desenvolvimento, a abertura fronteiriça afeta a irradiação de uma economia de serviços, situação 
que faz o comércio tornar-se a atividade primária, ou seja, a dinâmica que condiciona o restante dos setores e proporciona as cotas mais altas de renda e empregos. Consequentemente, a vida urbana também prevalece, o que, em alguns lugares como o Norte e o Sul, induz o surgimento de pequenas cidades que funcionam como enclaves de serviços, de modo que essas populações mantenham interações na região de fronteira (ALFONSO, 2005).

Portanto, as interações espaciais podem ser pensadas como uma parte integrante da existência de reprodução e de processos de transformação social, de deslocamento de pessoas, de mercadorias, de capital, de informação no espaço, em conformidade com a informação do espaço geográfico e do território (CORRÊA, 1997). A esse respeito, Moraes (2005) salienta que esse território não é apenas um recurso à força e à violência, também envolve legitimação do domínio e de poder praticados, o que redunda em formas jurídicas de reconhecimento do direito de soberania interna e externamente ao espaço. Isso faz com que esse território seja uma construção política que se reitera por meio de pactos e de disputas sociais.

Porém, esses lugares que sofrem essa transformação são representados por horizontalidades e verticalidades. Assim, as relações de horizontalidade, de um lado, podem ser determinadas pelos serviços que a cidade oferece em sua circunvizinha e que permitem os fluxos de movimentos da população, como comércio especializado, educação, circulação de mercadoria, serviços públicos, dentre outros. Já a verticalidade está minuciosamente incluída nos espaços em proporção e em diversas estruturas no processo de globalização, os quais se usam dos benefícios da informação, em qualidade da aptidão que esses territórios possuem, para unificar em redes os diversos espaços, de forma a inserir o processo de regionalização do espaço. Tal fenômeno traz novas práticas sociais por intermédio das interações espaciais, em que os arranjos espaciais provêm dos intercâmbios socialmente necessários, ou seja, de todas as trocas que se produzem na região como fato (SANTOS, 1996; 2006).

Por meio de configuração do espaço geográfico e territorial, Mezzadra (2015) aponta que o processo de fortalecimento e atravessamento da fronteira pode ocorrer em um momento no qual um conjunto de práticas de subjetividade pode entrar em conflito com as funções de regulamento dos fluxos desenvolvidos pela fronteira, questionando desse específico equilíbrio, que é objetivo de um sistema de controle de fronteira entre os dois Estados. Porém, a proliferação e a heterogeneidade das fronteiras no período da globalização colocam em crise uma diversificação entre interno e externo, componentes centrais da política e do direito internacional atual. Para Souza (1998), essa crise no modelo de Estado representa-se na limitação da eficiência das grandes instâncias de regulação mundial, na ampliação das desigualdades em todos os níveis e em todos os lugares, na velocidade da informação subvertendo os mercados mundiais. Ao dizer que as fronteiras se abrem 
aos produtos e se fecham aos homens, aumenta a impossibilidade do funcionamento do território em toda parte, com implicações diretas sobre a sobrevivência dos indivíduos.

Para Machado (2005), essa identidade da zona transfronteira é, a priori, o que a diferencia da fronteira em relação ao hinterland, geralmente um espaço consolidado do Estado territorial e nacional. A fronteira é caracterizada como um lugar das possibilidades em oposição aos espaços que já foram apropriados e organizacionalmente obstinados à mobilidade. Essa mobilidade, de acordo com Castillo (2017), pode ser efetuada pelo processo de migração e de acessibilidade de uma adaptação de um espaço urbano às necessidades das pessoas com diferentes tipos de limitação. Tal processo de mobilidade é determinado como um domínio associado à demografia. Portanto, ela passa a ser expandida por processo de movimentação e de locomoção que envolve a capacidade dos agentes, tais como fluxo de pessoas e empresa (os fluxos de comerciantes) que fazem movimentar bens e serviços, além das informações produtivas. Assim, esse fluxo de movimentação de agentes é medido por seu poder político e/ou econômico de desencadear fluxos materiais e fluxos informacionais.

Mezzadra (2015) relata que a fronteira não é uma coisa; na verdade, mantém uma relação social mediada pelas coisas. Isso significa que as fronteiras são instituições sociais complexas, às vezes, marcadas por tensões que se desenvolvem entre práticas de atravessamento e de fortalecimento. No decorrer de sua importância de movimento de pessoas no atravessamento de fronteiras, há uma mobilidade relevante nas dinâmicas fronteiriças, isto, não é apenas dos objetos em trânsitos, mas também dos atores políticos globais, dos Estados, das agências de governança e do capital. A Figura 3 mostra os fluxos de pessoas que atravessam a fronteira da cidade de Jimaní e o posto transfronteiriço de Malpasse - parte significante dos haitianos não voltaram ao país de origem.

Com base na análise da mobilidade, a fronteira passa a exercer uma função essencial de deslocamento, atravessamento de pessoas e de controle. Segundo Raffestin (1993), essa função de controle de fronteira tem por dever inspecionar a circulação dos homens, dos bens e da informação de uma maneira geral, no entanto tal controle de informação é muito difícil na maioria dos casos. Quanto à função fisscal, por muito tempo, ela representa o papel do instrumento da política econômica, por meio do protecionismo. Assim, se considerarmos as três primeiras funções, legal, de controle e fiscal, pode-se construir um sistema hierárquico de fronteiras que dá conta das relações de poder que podem se instaurar entre os atores políticos por intermédio das fronteiras.

Assim, as cidades de fronteira passam, às vezes, por uma série de problemas devido à falta de estrutura. Nesse sentido, as condições da passagem são drasticamente afetadas por eventos naturais, como, por exemplo, a inundação do Lago Azuei, que, no período de grande pluviosidade, inunda a região de fronteira de Jimaní e Malpasse/Fonds-Parisien, incluindo casas, prédios do 
governo e a rodovia que liga os dois países. Esse problema, contudo, não gera conflitos que obrigam os Estados a concordar com a necessidade de normatizar o transporte (HIDALGO, 2013).

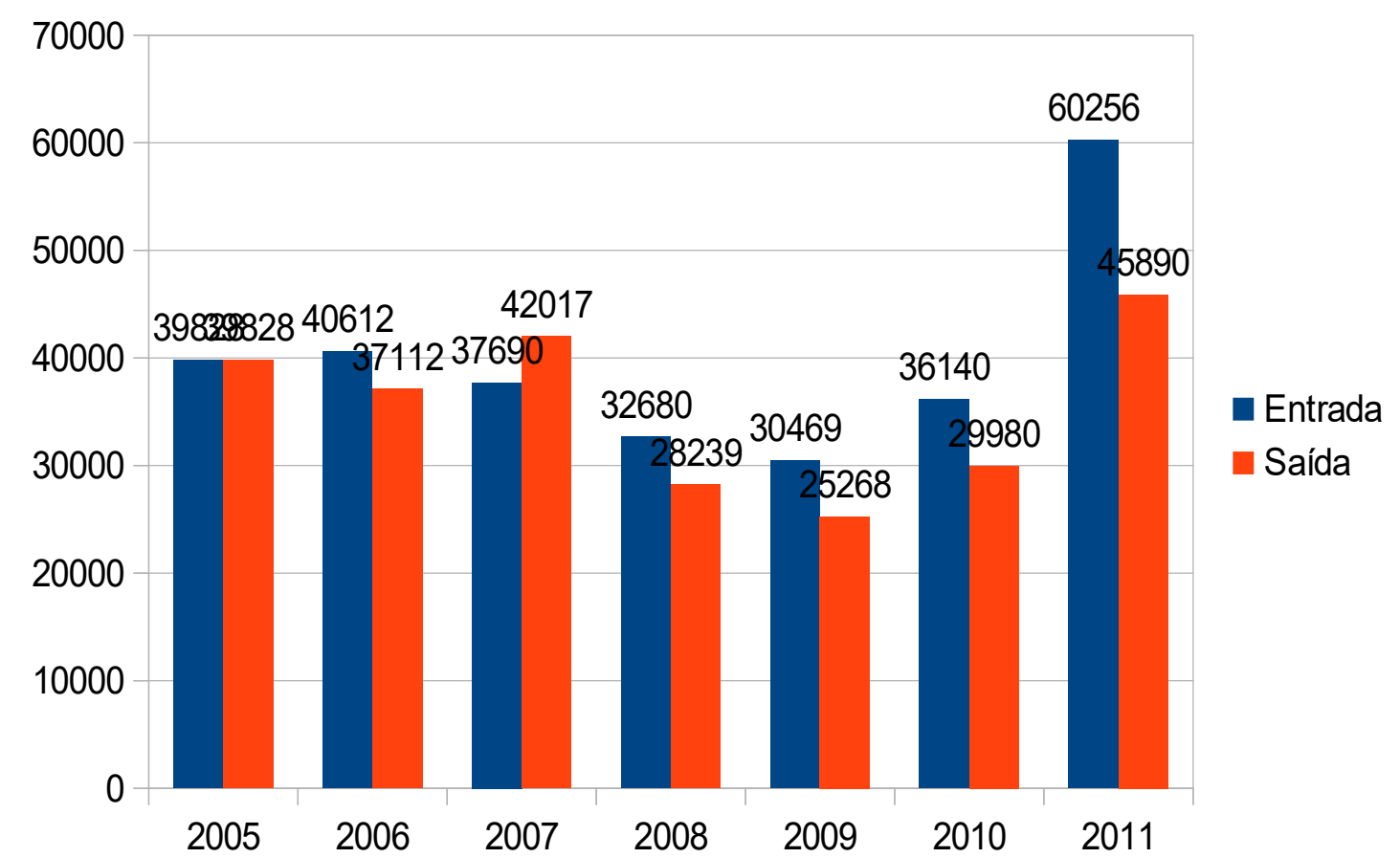

Figura 3 - Movimento internacional de pessoas atravessando a fronteira de Jimaní (Rep. Dominicana) e Malpasse (Haiti) no período de 2005 - 20011, por via terrestre.

Fonte: Escritório Nacional de Estatística - ONE (2015).

Segundo Hidalgo (2013), outros aspectos de problematização que acontecem na fronteira são a confusão e os conflitos que emergiram e têm o seu ponto de partida na ausência de regulamentos concebidos para abordar a realidade desse espaço. Tal fato ocorre mesmo diante de evidente fluxo comercial, da interação das comunidades e da participação nos padrões regionais de integração, pois a República Dominicana e o Haiti não implementaram mecanismos regulatórios nem a facilitação de negócios.

Em seguida, os problemas em Jimaní são questões de imigração de cidadãos haitianos, o tráfico de pessoas, de armas e de drogas, problemas que ocupam a maior parte do tempo e esforço das autoridades, do Ministério das Forças Armadas, do Departamento de Polícia e do Interior, do Centro de Especialização de Segurança das Fronteiras (CESFRON), da Direção Nacional de Controle de Drogas e da Direção Geral da Migração. Isso se deve à localização estratégica do país e especialmente à do município de Jimaní, tornando-se um território cobiçado para aqueles engajados em atividades ilícitas. Portanto, é o lugar preferido dos haitianos e haitianas que entram na República Dominicana na busca de uma vida melhor e de práticas de atividades comerciais na fronteira (PMDJ, 2016). 


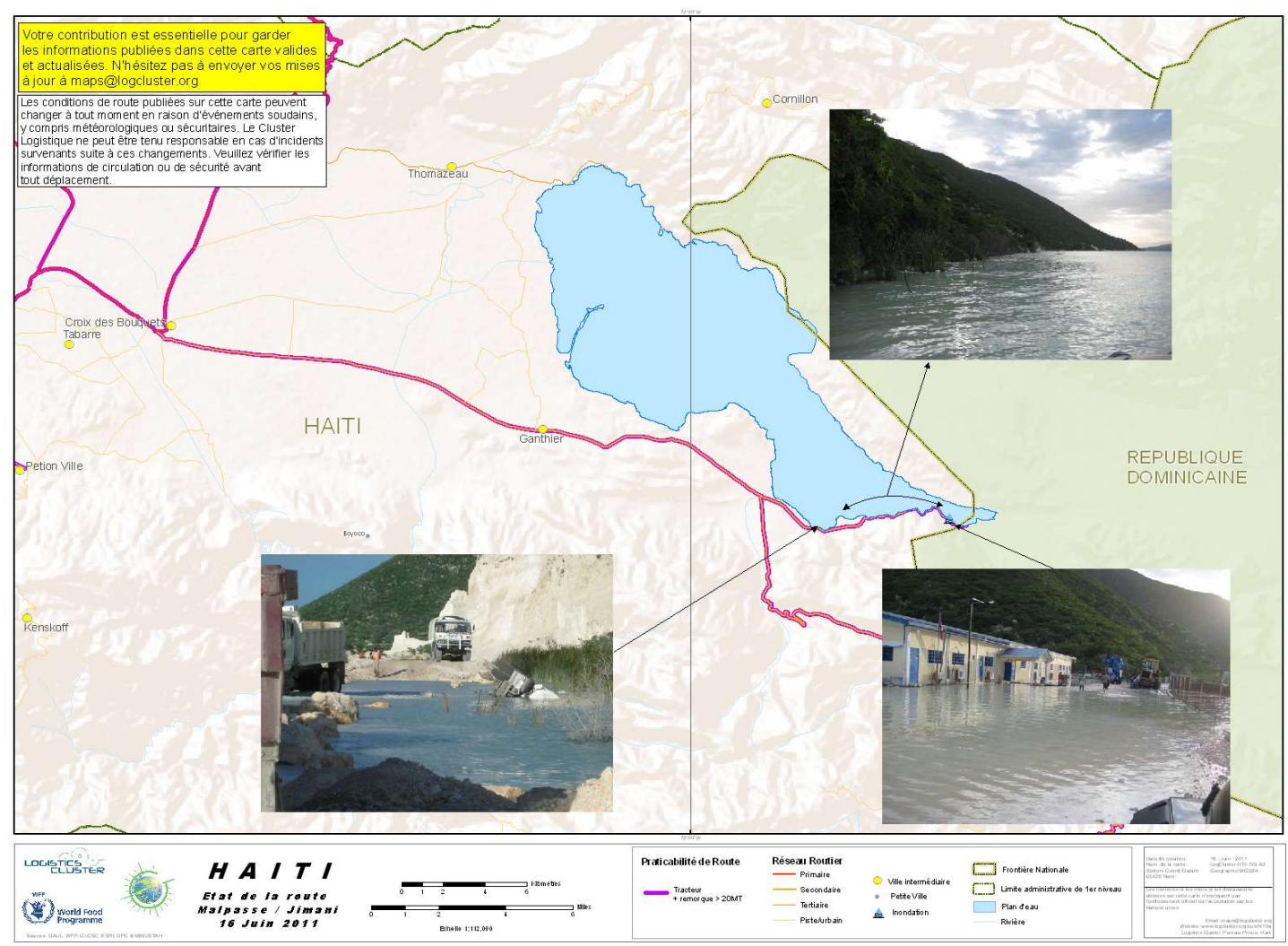

Figura 4 - Situação da rodovia de Malpasse-Jimaní.

Fonte: GAUL; WFP; GLCSC; ESRI; DPC; MINUSTAH (2011).

A ênfase dessa agenda de fronteira passou a restringida à relação geopolítica binacional entre 1936 e 1990, cujos sinais podem variar em função dos governos e dos fluxos migratórios, severamente controlados por ambos os Estados e, em particular, por altas patentes militares. Dessa forma, a inquisição de segurança ocupou um papel predominante qualitativa e quantitativamente. Essa agenda passou a ser aumentada devido à abertura do conteúdo econômico, enquanto a segurança começou a se relacionar mais com as novas questões de tráfico de drogas e terrorismo, em conexão direta com a falência das instituições militares e paramilitares do Haiti (ALFONSO, 2005).

Todavia, há gestão e de controle estabelecido pelo Estado dentre do limite dessa jurisdição do território. A faixa de fronteira é construída com visões bem definidas no decorrer da história, tanto entre a política entre os Estados nacionais, com a delimitação de soberania do poder central, quanto do espaço vivido e das interações entre populações nas áreas de fronteiras (FERRARI, 2014). De acordo Alfonso (2016), com o processo de abertura e fechamento da fronteira, o fluxo de pessoas, sobretudo da população haitiana que atravessa a fronteira, é descontrolado. Nesse contexto, a significação da preservação dos pontos básicos de qualquer agenda de fronteira, ou seja, de investimento, de segurança, de migração, de comércio, e do meio ambiente, ganha ênfase em oposição ao interesse das inquisições geopolíticas, estratégicas e comerciais entre os Estados. 


\section{FRONTEIRA: LUGAR DE INTERAÇÃO, INTEGRAÇÃO ESPACIAL E DE TROCAS DE MERCADORIAS ENTRE JIMANÍ E MALPASSE/FONDS-PARISIEN}

A construção de um modelo de fronteira é uma atividade perigosa em virtude da complexidade dos objetos, das transformações do território e do espaço geográfico. Portanto, as fronteiras podem evoluir em suas formas espaciais e em suas funções por meio de uma linha fixa permutada numa rede de controle construída sobre todos os pontos de entrada do território nacional, permitindo um acompanhamento dos movimentos e dos caminhos (RETAILLÉ, 2011; HAMEZ, AMILHAT-SZARY, PARIS et al., 2013). Essas inquietações dos Estados sobre o controle do movimento contradizem o aumento quantitativo no fluxo de bens materiais e imateriais que transitam na fronteira, tais como: realocações e deslocamentos, cadeias globais e fluxos humanos que acompanham o crescimento das principais regiões, as áreas metropolitanas e seus requisitos combinados de mão de obra altamente qualificada e não qualificada. Portanto, esse resultado apresentado pode ser usado como uma contradição entre abertura e controle (POPESCU, 2012; HAMEZ, AMILHAT-SZARY, PARIS et al., 2013).

Cabe observar que tais práticas de atividades de desenvolvimento econômico da região de fronteira possuem consequências sociais, demográficas e econômicas, de tal modo que as cidades fronteiriças ainda ocupam um lugar excepcional, tornando-se ainda mais atrativas (MACIAS, 2004) pela população estabelecida na fronteira. Portanto, esse limite territorial, que passa a ser exibido nos postos de controle, localizado a alguns metros da fronteira entre a cidade de Jimaní e o posto de fronteira de Malpasse/Fonds-Parisien, é uma faixa simbólica dando lugar a uma vida cotidiana nas relações de trocas de mercadorias (REDON, 2010). O município de Jimaní mantém relações comerciais com diversas comunidades da República do Haiti, como Malpasse/Fonds-Parisien, Gantier, Fonds-Verrettes, Porto Prince e com os municípios de Duvergé, Descubierta, Neyba, entre outros (PMDJ, 2016).

Nesse contexto, essa faixa de fronteira entre os dois Estados representa $51 \%$ da passagem de mercadoria da República Dominicana. Essa parte da fronteira é muito povoada do lado haitiano, mesmo que não haja cidade próxima a ela, mas há duas localidades que vivem do contrabando, do comércio ilegal e informal de mercadorias e da exploração de areia, como a cidade Fonds-Parisien, a $10 \mathrm{~km}$ da fronteira de Jimaní (MOUDDEN, 2006). E essas práticas de atividades comerciais funcionam particularmente de segunda-feira a sexta-feira na fronteira (HIDALGO, 2013; MOUDDEN, 2006; PMDJ, 2016).

A região de fronteira de Jimaní e o posto transfronteiriço de Malpasse/Fonds-Parisien, chamados por seus povos de "terra de ninguém", são o lugar onde são feitas informalmente as operações de negócios mais relevantes, denominado pelos governos desses país de mercado Binacional Jimaní. Esse mercado conduz suas operações a céu aberto, em vans, mesas improvisadas 
e lojas dos quais participam centenas de pessoas no mercado transfronteiriço. Essas pessoas comercializam produtos como detergentes, açúcar, café, sal, óleo, farinha, feijão, arenque, bacalhau, legumes, sardinha, roupas, perfumes, sapatos, carteiras, cosméticos, joias, salsichas, bananas, batata-doce, mandioca, pèpès, frango, carne bovina, produtos enlatados, entre outros, conforme apresentado nas Figuras 5 e 6.

Trata-se de um mercado caracterizado pela interação de dominicanos e haitianos, falantes de duas línguas diferentes (espanhol e crioulo haitiano) (HIDALGO, 2013). Por meio dessas atividades desenvolvidas na fronteira, grande parte das pessoas de ambos dos Estados deslocam-se para comprar e vender bens e serviços no mercado transfronteiriço de Jimaní e de Malpasse/FondsParisien, um dos pontos mais dinamizados e movimentados da circulação do sistema econômico do Haiti com o Estado vizinho.

O mercado da cidade de Jimaní e Malpasse/Fonds-Parisien atua com taxas muito altas de insalubridade, já que se observa a venda de produtos, frutas, legumes e verduras colocadas no chão e expostas ao sol e à poeira ao longo do dia. Nesse mercado, as donas de casa do município de Jimaní se reúnem todos os dias em busca de obter os produtos da cesta básica a um custo menor e também de roupas e calçados de pèpès baratos. É um negócio estabelecido em grande parte por cidadãos haitianos (PMDJ, 2016).

Esse mercado estabelecido na fronteira oferece uma grande oportunidade para ambas as populações. O potencial de troca comercial apresentado pela cidade de Jimaní e pelo posto de Malpasse/Fonds-Parisien gera grande volume de vendas para os haitianos e traz importante benefício para a população da cidade de fronteira.

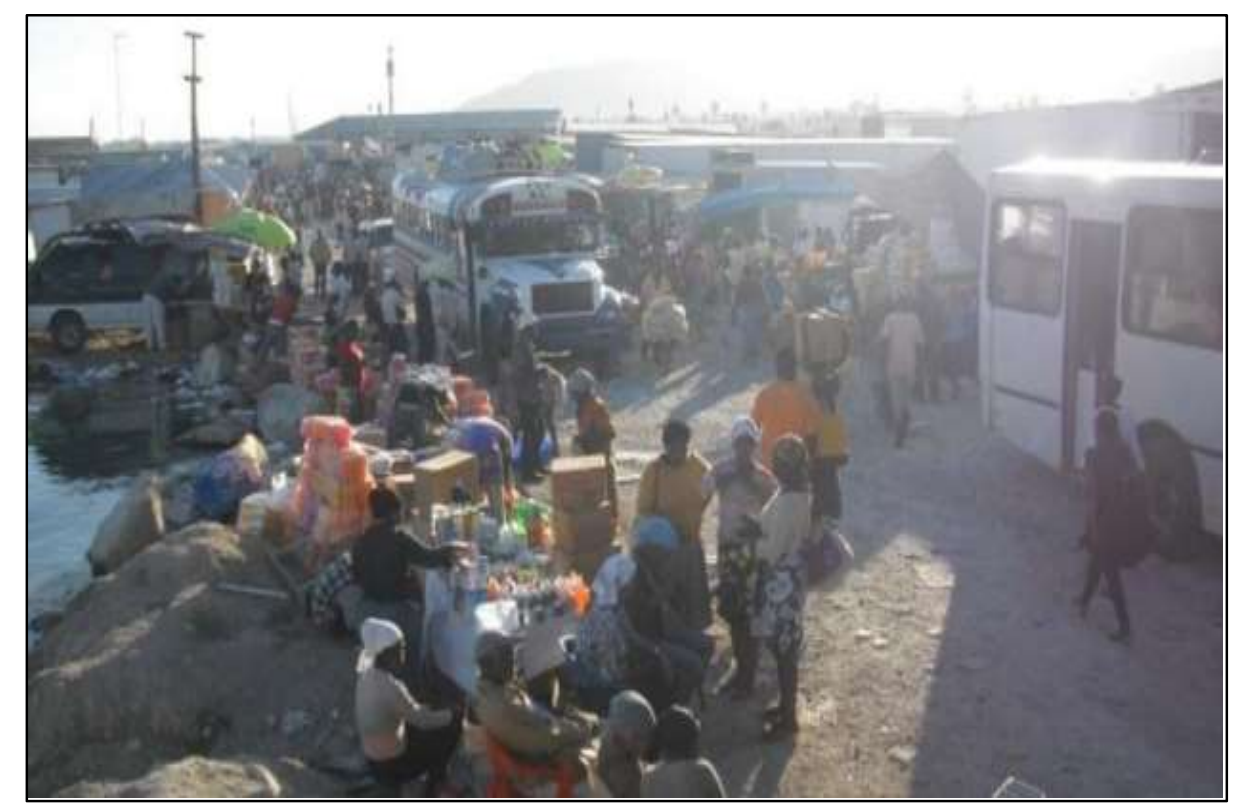

Figura 5 - Comerciantes no mercado binacional de Jimani - Malpasse. Fonte: PMDJ (2016). 


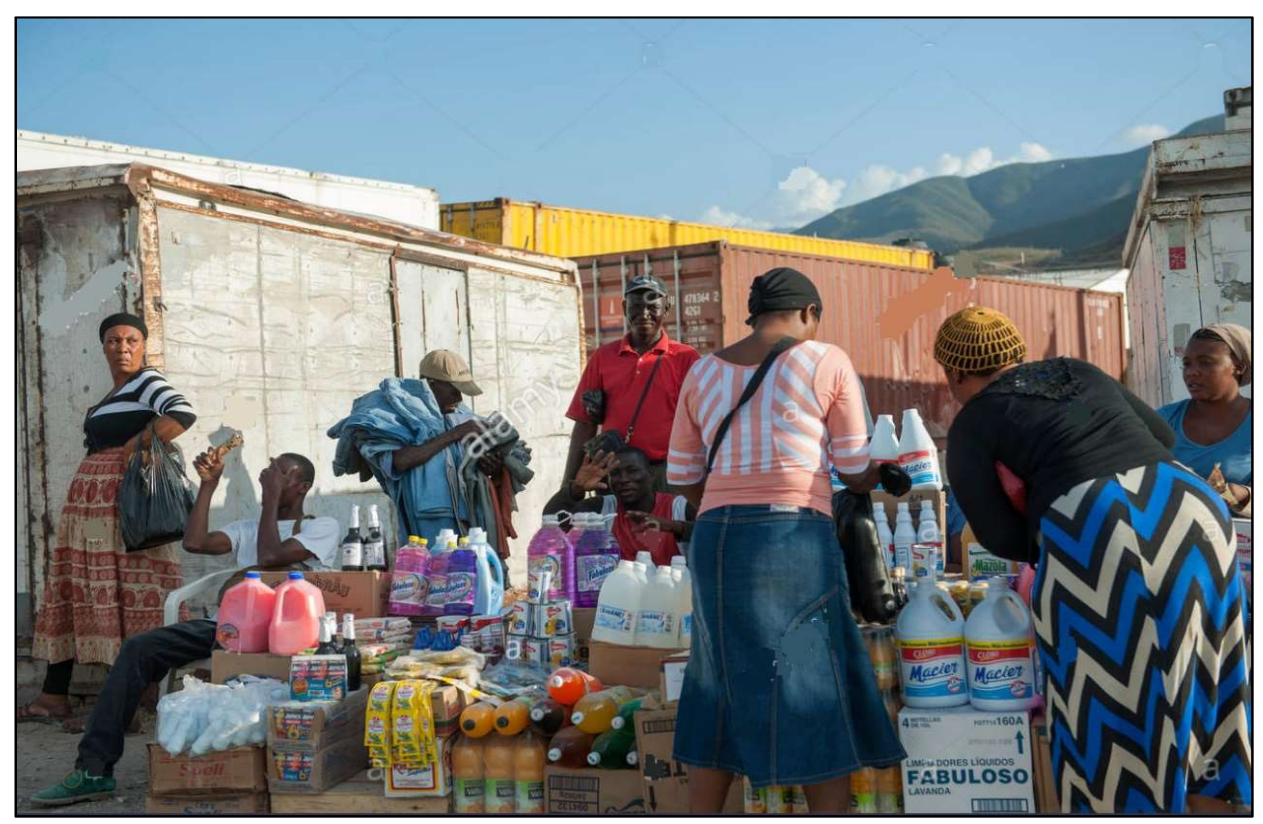

Figura 6 - Comerciantes e compradores no mercado de Jimaní-Malpasse.

Fonte: Alamy Stock foto (2010).

Para Alfonso (2016), as práticas de atividades comerciais estabelecidas na fronteira padecem de uma ausência crônica de institucionalidade e normatividade. Não há políticas estatais integracionistas, nem mesmo acordos binacionais específicos sobre as atividades praticadas na fronteira, tais como de comércio, investimentos, migração, segurança ou de recursos ambiental. No lado dominicano, a institucionalidade é fraca e não há nada semelhante a um regime legal de fronteira. No entanto, no lado haitiano, a situação é ainda mais dramática, e a faixa de fronteira aparece como um verdadeiro deserto institucional. De fato, as regionalizações ocorreram da atividade de mercado ou empurradas por instituições locais cujo escopo foi limitado por ambientes adversos.

Nessa atividade desenvolvida na região de fronteira, segundo Raffestin (1993), a demarcação ocorrida entre os dois Estados pode facilitar o exercício das funções legais e o controle fiscal. Com efeito, a linha fronteiriça adquire diferentes significados segundo as funções do investimento. Todavia, uma função legal delimitou uma área no interior na qual prevalecia um conjunto de instituições. Desse modo, Bourgeois (2016) argumenta que o comércio que se desenvolve na faixa de fronteira entre o Haiti e a República Dominicana usa o espaço de fronteira de particularidades diversas, tanto formal e informal.

Para Redon (2010), esse tipo de relação comercial não é um fenômeno mais recente que evolui com a situação política e econômica. Portanto, as trocas de mercadorias atuais praticadas na fronteira são de caracterização multifacetada, improváveis de quantificar e coexistem com um conjunto de comércio legal e ilegal, de comércio formal e informal estabelecidos na fronteira. Dessa 
forma, Bourgeois (2016) reiterando o pensamento de Bruno Lautier (1994) e a ideia de Constantin (1996), sustenta essa dimensão da unidade de atividade do comércio e de seu funcionamento em vinculação à lei, apresentado duas linhas de atividades comerciais entre formal e informal na fronteira da República Dominicana, extensivamente distribuídas por parte de toda a população.

Nesse contexto, Oliveira (2008) ressalva que essas atividades informais são geralmente relevantes para as transformações por meio das relações de produção, particularmente para as quais promovem as atividades de emprego, prejudicam a dinâmica interna e da vida cotidiana e também o processo de reprodução da força de trabalho, associando-se às inquisições, como o uso de espaços públicos por atividades comerciais.

Para Foucher (1991), uma função fiscal garante renda ao Estado, cobrando impostos sobre transações comerciais e vistos de faturamento para o movimento de pessoas. No entanto, a razão para a ausência de fronteiras é, no campo econômico, cortar os limites tarifários, os obstáculos a um mercado fluido em virtude dos custos adicionais que eles impõem. Assim, a função de controle se vincula à circulação de pessoas por meio da política de vistos, na ausência de acordos de reciprocidade, e regimes específicos de facilitação podem ser concedidos a populações fronteiriças.

Portanto, a circulação de produtos nos mercados fronteiriços reduz a capacidade de coletar receita e de implementar uma política comercial porque não há controle sistemático sobre o que está acontecendo em toda a fronteira. Esses mercados são um meio mais eficaz para os exportadores/importadores contornarem as alfândegas e, assim, evitarem o pagamento de taxas. Geralmente, isso foi feito para atomizar a mercadoria de fronteira: dividir um grande volume de mercadoria entre várias pessoas para transportá-las, contrabandear através da fronteira e, em seguida, recombinar as mercadorias em vans ou caminhões de tamanho médio através da zona fronteiriça. Esses produtos podem, então, ser transportados em todo o país e vendidos sem pagamento de impostos pelo serviço aduaneiro (CFI, 2016).

Conforme relatado e registrado pelo governo dominicano, dados mostram que o Haiti registra 29\% de importações por via terrestre; as importações por via marítima são de $60 \%$; e $20 \%$ ocorrem por via aérea, em um valor estimado de US\$ 300.000 a US\$600.000. A porcentagem de importações terrestres é menor porque Malpasse/Fonds-Parisien é um lugar onde as importações facilitadas e informais mais densas entram no Haiti e, também, pela potencial fraude no serviço aduaneiro.

Os fluxos de mercadorias que cruzam a fronteira Malpasse/Fonds-Parisien-Jimani foram estimados em US\$ 565 milhões. Isso pode ser explicado pela proximidade com a cidade Porto Príncipe, onde há uma concentração de empresas manufatureiras. Porém, 40\% delas são registradas pela Alfândega do Haiti, e a maior demanda do consumidor é representada por insumos de fabricação, resultando um volume de importações relativamente maior que os $60 \%$, de modo que 
grande parte dessas importações facilitadas são destinas a roupas e vestuários (CFI, 2016). Esse fluxo de comércio ilegal ou informal que circula na fronteira representa um déficit muito grande para a economia haitiana, uma vez que o Estado não tem o controle dessas mercadorias. Enquanto isso, move a economia urbana e permite à população responder às necessidades de sua família.

\section{CONSIDERAÇÕES FINAIS}

Este artigo buscou discutir a abordagem sobre as zonas transfronteiriças por meio da delimitação territorial entre a cidade de Jimaní e o Posto transfronteiriço de Malpasse/FondsParisien. A fronteira é um lugar onde as duas populações compartilham suas vivências econômicas, políticas e de práticas socioculturais. Como a fronteira de Jimaní e Malpasse é um dos principais postos fronteiriços que correspondem a mais da metade do comércio entre os países, o Estado deve tomar medidas necessárias para proteger e controlar o fluxo de mercadorias que transitam pela fronteira. Porém, esse tipo de comércio praticado na fronteira e a relação comercial mantida entre os dois Estados perfuram a percepção da territorialidade nacional, reforçando a unidade geográfica do território da ilha. Tais atividades ajudam a transformar a realidade da fronteira de um perigo para uma promessa econômica. Essa vantagem e esse equilíbrio reverberam em favor da República Dominicana, devido à fraqueza logística e estrutural do território haitiano, além de os pontos de acesso para transporte de mercadorias serem porosos. Esses mercados binacionais negociam desproporcionalmente os bens dominicanos, gerando certo desequilíbrio geográfico, mas que evidencia uma interdependência benéfica entre os dois países.

\section{REFERÊNCIAS}

ALFONSO, H. D. La regionalización precaria en la frontera dominico/haitiana. Revista de Estudios Transfronterizos, v. 16, n. 1, p. 15-41, 2016.

ALFONSO, H. D.; DE JESUS CERDENO, S. De problemas y oportunidades: intermediación urbana fronteriza em República Dominicana. Revista Mexicana de Sociologia, Cidade do México, v. 67 , n. 1, p. 99-126, 2005.

ANCEL, J. Géographie des fronteires. Paris: Gallimard, 1938.

BOURGEOIS, C. Os "pèpès" contra o Estado: circulação de artigos têxteis de segunda mão na fronteira Haiti-República Dominicana e negociações sobre sua comercialização. Boletim Gaúcho de Geografia, v. 43, n. 1, p. 36-59, 2016.

CENTRE DE FACILITATION DES INVESTISSEMENTS (CFI). Les flux commerciaux entre Haïti et la Republique Dominicaine. Opportunités pour acroître la production haïtienne. Port au Prince, 2016. Disponível em: http://www.haitilibre.com/docs/flux2.pdf. Acesso em: 20 jan. 2019. 
CORRÊA, R. L. Interações espaciais. In: CASTRO, I. E.; GOMES, P. C. C.; CORRÊA, R. L. (Orgs.). Explorações Geográficas. Rio de Janeiro: Bertrand Brasil, 1997. p. 279-318.

FERRARI, M. As noções de fronteiras geográficas. Revista Perspectiva Geográfica, v. 9, n. 10, p. $1-25,2014$.

FOUCHER, M. Fronts et Frontières. Un tour du monde géopolitique. Paris: Fayard, 1991. 690p.

FOUCHER, M. L'obsession des frontières. Paris: Ed. Perrin, 2007. 240p.

GOTTMANN, J. The evolution of the concept of territory. Social Science Information, v. 14, n. 3, p. 29-47, 1975.

HAMEZ, G.; AMILHAT-SZARY, A. L.; PARIS, D.; REITEL, B.; WALTHER, O. Guest Editorial: Modèles des frontières. Revue Belge de Géographie, v. 1, p. 1-7, 2013.

MACIAS, M. C. Évolution de l'enclave frontalière de la basse Californie de la zone libre au libreéchange. Cahiers des Amériques Latines, v. 47, p. 88-108, 2004.

MACHADO, L. O. Estado, territorialidade, rede. In: SILVEIRA, M. L. (Org.). Cidades-gêmeas na zona de fronteira sul-americana. Continente em Chamas. Globalização e Território na América Latina. Rio Janeiro: Civilização Brasileira, 2005. p. 246-284.

MEZZADRA, S. Dossiê: Migrações e fronteiras. Multiplicação das fronteiras e práticas de mobilidade. Rev. Interdiscip. Mobil. Hum., Brasília, v. 23, n. 44, p. 11-30, 2015.

MORAES, A. C. R. Território e história no Brasil. 2. ed. São Paulo: Annablume, 2005. 198p.

MOUDDEN, L. P. E. Villes à la frontière et transformation de l' espace: le cas d' Haïti et la République Dominicaine. 2006. Tese (Doutorado) - Faculté de l' Environnement Naturel, Architectural et Construit, 2006.

PMDJ - PLAN MUNICIPAL DE DESARROLlO JIMANÍ. Pueblo de dos lagos, comercial, $\begin{array}{llllll}\text { solidario } & y & \text { de } & \text { paz, } & \text { 2016-2020. } & \text { Disponível }\end{array}$ http://sismap.gob.do/Municipal/uploads/evidencias/636172249029782420-PMD-JIMANI.pdf Acesso em: 20 set. 2018.

RAFFESTIN, C. Éléments pour une Problématique des Régions Frontalières'. L'Espace Géographique, Paris, n. 1, 1974, p. 12-18. Paris, 1974.

RAFFESTIN, C. Por uma geografía de poder. 1. ed. São Paulo: Ática, 1993. 269p.

RETAILLE D. La transformation des formes de la limite. Journal of Urban Research, 2011. Disponível em: http://articulo.revues.org/1723\&gt. Acesso em: 15 mai. 2018.

RIBEIRO, A. C. T. Regionalização: fato e ferramenta. In: LIMONAD, E.; HAESBAERT, R.; MOREIRA, R. (Orgs.). Brasil, século XXI - por uma nova regionalização? Agentes, processos e escalas. São Paulo: Max Limonad, 2004. p. 194-212.

SANTOS, M. A natureza do espaço. Técnica e tempo, razão e emoção. 2. ed. São Paulo: Hucitec, 1996. 259p. 
SANTOS, M. Metamorfoses do espaço habitado. 3. ed. São Paulo: Hucitec, 2008. 163p.

SANTOS, M. Pensando o espaço do homem. 1. ed. São Paulo: Hucitec, 1982. 96p.

SILVEIRA, F. L. A. As complexidades da noção de fronteira, algumas reflexões. Caderno Pós Ciências Sociais, São Luís, v. 2, n. 3, 2005.

SOUZA, E. B. C.; GEMELLI, V. Território, região e fronteira: Análise geográfica Integrada da Fronteira Brasil/Paraguai. 2011. Revista brasileira de Estudos Urbanos e Regionais, v. 13, n. 2, p.101-116, 2011.

THEODAT, J. M. Haiti-Quisqueya: Une double insularité. Mappemonde, Avignon, v. 51, n. 3, p. 7-11, 1998.

Trabalho recebido em 03/07/2019

Trabalho aceito em 11/07/19 